\title{
Ammonia Inhibition in Oleaginous Microalgae
}

22 *Corresponding author tel: (203) 432-4385; fax: (203) 432-4387; email: jordan.peccia@yale.edu 


\section{ABSTRACT}

25 Waste-streams containing nitrogen (commonly as $\mathrm{NH}_{3} / \mathrm{NH}_{4}{ }^{+}$) have been promoted as a means

26 to lower the energy burden and improve the overall sustainability of microalgae-based fuel and

27 chemical production. However, beyond a concentration threshold, ammonia $\left(\mathrm{NH}_{3}\right)$ is toxic to

28 many microalgae. This study investigated the ammonia tolerances of oleaginous microalgae.

29 Four microalgae that are often considered in biofuel production studies (Neochloris

30 oleoabundans, Dunaliella tertiolecta, Chlorella sorokiniana and Nannochloropsis oculata) were

31 grown in batch reactors maintained at 10 different $\mathrm{NH}_{4} \mathrm{Cl}$ concentrations at a constant $\mathrm{pH}=8$.

32 Growth rates and lipid profiles were monitored. Ammonia acted as an inhibiting substrate for $N$.

33 oleoabundans and D. tertiolecta at 2.3 and $3.3 \mathrm{mg} \mathrm{L}^{-1} \mathrm{NH}_{3}$, respectively. Growth rates for $C$.

34 sorokiniana and $N$. oculata were largely unaffected by ammonia concentrations. D. tertiolecta

35 demonstrated significant neutral lipid alterations during ammonia inhibition.

36 Keywords: biofuels, ammonia, nitrogen, nitrogen recycle, bioenergy, wastewater

\section{INTRODUCTION}

40 Biofuel sustainability may be challenged by the energy burden associated with the production

41 of nitrogen fertilizers needed for microalgae cultivation. Nitrogen demand is dependent on the

42 type of biofuel feedstock, with $1.9 \mathrm{~g} \mathrm{~N} \mathrm{MJ}^{-1}$ of fuel required for corn derived ethanol and $0.18 \mathrm{~g}$

$43 \mathrm{~N} \mathrm{MJ}^{-1}$ for soy-based biodiesel $[1,2]$. These nitrogen demands are low when compared to biofuels

44 from microalgae, which have projected $\mathrm{N}$ demands ranging from $6.6-46.9 \mathrm{~g} \mathrm{~N} \mathrm{MJ}^{-1}$ biodiesel

45 [3]. The nitrogen required for microalgae cultivation represents a major energy burden,

46 accounting for an estimated $45 \%$ of the total energy input [4,5]. One energy saving approach that

47 is commonly outlined in life cycle analyses includes the utilization of N-containing waste 
48 streams such as secondary wastewater treatment plant effluent, anaerobic digester centrate, dairy

49 waste runoff or post lipid-extracted biomass [6-8]. Nitrogen in these waste streams is recovered

50 as $\mathrm{NH}_{3} / \mathrm{NH}_{4}{ }^{+}$, a common byproduct of biomass degradation.

51 Due to fewer biochemical steps for incorporation of $\mathrm{NH}_{3} / \mathrm{NH}_{4}{ }^{+}$into amino acids and the low

52 molecular weight, it is often assumed that microalgae will demonstrate preferential uptake of

$53 \mathrm{NH}_{3} / \mathrm{NH}_{4}{ }^{+}$over other forms of nitrogen [9]. However, experimental data points to a complexity

54 of nitrogen assimilation that does not allow for a universal preference statement. In many

55 phototrophic microorganisms, unionized ammonia can interfere with autotrophic metabolism

$56[10,11]$, either by ligating to the photosystem II oxygen evolution reaction core thereby creating

57 increased photo sensitivity that eventually results in increased photosystem damage $[12,13]$,

58 and/or by uncoupling photophosphorylation by reducing the $\mathrm{pH}$ gradient need to power the

59 conversion of ADP to ATP [14]. Nitrogen substrate affinities within an organism may also be

60 impacted by available $\mathrm{N}$ concentration, growth phase and light regimes [15-19].

61 Nitrogen preferences or $\mathrm{NH}_{3} / \mathrm{NH}_{4}{ }^{+}$inhibition are not well documented in common strains

62 of oleaginous microalgae at concentrations relevant for biofuel production. In this study we

63 investigated the ammonia tolerances of the oleaginous microalgae Nannochloropsis oculata,

64 Dunaliella tertiolecta, Neochloris oleoabundans and Chlorella sorokiniana. Tolerance is

65 assessed by inhibition of growth and neutral cellular lipid production and characterization as a

66 function of nitrogen type $\left(\mathrm{NO}_{3}{ }^{-}\right.$or $\left.\mathrm{NH}_{3} / \mathrm{NH}_{4}{ }^{+}\right)$and concentration. This work directly addresses

67 critical assumption in many life cycle analyses and microalgae biorefinery schemes' surrounding

68 nutrient recycling for microalgae derived biofuel production, and identifies relevant free

69 ammonia concentrations and oleaginous microalgae that can be used for production in systems

70 with high $\mathrm{NH}_{3} / \mathrm{NH}_{4}{ }^{+}$content. 


\section{2. METHODS}

\section{2.1. Species and Media Selection}

74 Four microalgae species were chosen based upon their elevated lipid content and rapid growth

75 rates [20]. All species were obtained from the microalgae library at the University of Texas at

76 Austin and include the marine isolates Nannochloropsis oculata (UTEX LB 2341) and

77 Dunaliella tertiolecta (UTEX LB 999), and the freshwater isolates Neochloris oleoabundans

78 (UTEX 1184) and Chlorella sorokiniana (UTEX 1602). Freshwater species were grown in a

79 modified Bold $3 \mathrm{~N}$ media [21] with $1 / 3^{\text {rd }} \mathrm{K}_{2} \mathrm{HPO}_{4}$ and $\mathrm{KH}_{2} \mathrm{PO}_{4}$ buffer concentrations to prevent

80 phosphate interference with ammonia measurements. Marine species were grown in enriched

81 seawater Erdschreiber's Media [22]. In both media, the nitrogen concentrations were modified

82 for experimental conditions as outlined below.

83

\section{2.2. Growth Conditions}

85 Growth experiments were conducted in 1L Erlenmeyer flask batch reactors that were sparged

86 via porous stone diffusers with air treated by an activated carbon filter (Koby Inc, MA, USA)

87 and a $0.45 \mu \mathrm{m}$ pore-size polycarbonate membrane. Air-flow was metered by mass flow

88 controllers (Cole-Parmer Instrument Company, IL, USA) at a rate of $0.6 \mathrm{~L}$ air $\mathrm{min}^{-1} \mathrm{~L}^{-1}$. Reactors

89 were well mixed using magnetic stir bars or an orbital mixer at $200 \mathrm{rpm}$ and were exposed to

90 fluorescent light with a photosynthetic flux density of $240 \mu \mathrm{mol}$ photons $\mathrm{m}^{-2} \mathrm{~s}^{-1}$ (Thermo Fisher

91 Scientific, MA, USA) and a 14/10 light/dark cycle. Seed cultures were grown with $\mathrm{NO}_{3}{ }^{-}$

92 enriched media for 7 to 10 days, after which biomass was harvested through centrifugation (RC-

936 Plus, ThermoScientific, DE, USA) at $5000 \mathrm{~g}$ for 5 minutes, and cells were washed with 
94 nitrogen-free growth media. Seed cultures were enumerated by light microscopy using a 95 hemacytometer counting chamber (Hausser Scientific, PA, USA). Inocula for all $N$. 96 oleoabundans, C. sorokiniana, and N. oculata experiments were $1.0 \times 10^{6}$ cells into $600 \mathrm{~mL}$ of 97 media. Inocula for the D. tertiolecta experiments were $5.0 \times 10^{5}$ cells into $600 \mathrm{~mL}$ of media due 98 to the large size of the cells, which increase the initial optical density.

99 Each experimental run lasted 10 days and biological triplicates were performed. Ammonium 100 chloride was added to the microalga growth media to form ten different concentrations that were 101 maintained throughout the growth cycle. Concentrations included the following: 10, 20, 50, 100, $102200,300,400,500,750,1000 \mathrm{mg} \mathrm{L}^{-1} \mathrm{NH}_{4} \mathrm{Cl}$. To control the concentration of free ammonia $103\left(\mathrm{NH}_{3}\right)$, experimental media contained 50mM HEPES (American Bioanalytical, MA, USA) 104 buffering agent adjusted to a $\mathrm{pH}$ of 8 . At $\mathrm{pH} 8$, the $\mathrm{NH}_{3}\left(\mathrm{NH}_{4}{ }^{+}\right)$concentrations were: 0.2 (3.2), 1050.3 (6.4), 0.8 (16.1), 1.7 (32.2), 3.3 (64.4), 6.7 (128.8), 8.4 (161.0), 12.5 (241.5), 16.7 (321.9) mg

$106 \mathrm{~L}^{-1}$. Control experiments revealed that HEPES did not act as an $\mathrm{N}$-source for these microalgae.

107 HEPES and no HEPES controls were also tested with both $N$. oculata and D. tertiolecta and no 108 growth inhibition due to HEPES was observed.

109 Inorganic nitrogen was converted to ammonia and measured with a two-step process using the 110 Total Inorganic Nitrogen Pretreatment Reagent Set and Nitrogen-Ammonia Reagent Set, TNT,

111 AmVer (Salicylate), High Range (HACH, CO, USA). Calibration curves relating absorption and $112 \mathrm{NH}_{4}^{+}+\mathrm{NH}_{3}$ concentrations were created to monitor nitrogen concentrations. Ammonium 113 concentrations were calculated using $\mathrm{NH}_{3} / \mathrm{NH}_{4}{ }^{+}$equilibria. To maintain constant total nitrogen

114 concentrations and balance between $\mathrm{NH}_{4}{ }^{+}$and $\mathrm{NH}_{3}, \mathrm{pH}$ was closely monitored and nitrogen was 115 replenished as needed with a filter sterilized $\mathrm{NH}_{4} \mathrm{Cl}$ solution. "The reactor $\mathrm{pH}$ values, including 116 variation throughout growth experiments, are presented in Table S2." 


\section{2.3. Sampling and Analysis}

119 Samples were taken every other day in the initial stage of the experiments and daily during

120 the mid-exponential phase (days 5-10). Five milliliters $(5 \mathrm{~mL})$ were collected and tested for $\mathrm{pH}$

121 to insure system stability and constant free ammonia concentration. Cell density was measured in

122 triplicate through photospectroscopy (Helios Delta, Thermo Fisher Scientific, MA, USA) at a

123 wavelength of $655 \mathrm{~nm}$. To create cell concentration versus absorbance ratios, samples of known

124 absorbance were checked for cell numbers using light microscopy and hemacytometer-based

125 counting. In addition to growth, total lipids and fatty acid characterization was performed. Total

126 cellular lipid content was determined using cells harvested after the $10^{\text {th }}$ day of the experiments

127 (late log phase), collected via centrifugation, freeze dried and stored in a $-80{ }^{0} \mathrm{C}$ freezer until

128 lipid extraction. Neutral lipids were extracted using a modified Folch method with 2:1

129 chloroform: methanol solution [23]. Total lipids were then transesterified, and fatty acid methyl

130 esters (FAME) [24] were analyzed as an indicator for triacylglyceride content via gas

131 chromatography (HP 6890 A, Agilent Technology, CA, USA) equipped with a SP-2560

132 Capillary Column (Sigma-Aldrich, MO, USA). Peaks were identified and quantified via 133 standardization using a Supelco® 37 component FAME mix (Sigma Aldrich, MO, USA).

\section{2.4. Inhibition Kinetics Modeling}

136 After completion of growth experiments, linear regression over the mid-exponential growth

137 phase was used to estimate growth rates at each ammonia concentration. Data points from 138 replicate samples were aggregated for a single linear regression for model fitting. Characteristic 
139 growth experiment profiles are provided in Figure S1. Inhibition kinetics were evaluated using

140 the Monod-based substrate inhibition model developed by Han and Levenspiel [25] equation 1:

$$
R_{C}=k\left(1-C_{s} / K_{i}\right)^{n} \frac{C_{S}}{C_{S}+K_{m}\left(1-C_{S} / K_{i}\right)^{m}}
$$

144 Where $R_{c}$ is the cell growth rate (cells time ${ }^{-1}$ ), $k_{M A X}$ is the maximum growth rate (cells time ${ }^{-}$

$\left.145^{1}\right), C_{s}$ is the substrate concentration $\left(\mathrm{mg} \mathrm{L}^{-1}\right), K_{i}$ is the inhibition constant $\left(\mathrm{mg} \mathrm{L}^{-1}\right), K_{m}$ is the

146 Monod half saturation concentration of growth kinetics $\left(\mathrm{mg} \mathrm{L}^{-1}\right)$ and $m$ and $n$ are unit-less

147 constants that account for observed changes to $k$ and $K_{m}$.

\section{2.5. Statistics}

149 All growth experiments were conducted in biological triplicate. The resulting algal 150 concentration data for each treatment was aggregated and linearly regressed to obtain growth

151 rates and standard deviations for each species and each $\mathrm{NH}_{4}{ }^{+} / \mathrm{NH}_{3}$ concentration. Inhibition

152 parameters from eq. 1 were determined by optimized model fit to the observed data through

153 minimizing residuals via the sum of least squares. Goodness of fit was evaluated through the

154 root mean square deviation (RMSD). All lipid analysis was performed in triplicate and standard

155 deviations were calculated for each lipid fraction. T-tests with reported p-values were used to 156 compare lipid content among the different species and different nitrogen conditions. 


\section{$162 \quad 3 . \quad$ RESULTS AND DISCUSSION}

\section{$163 \quad 3.1$ Effects of Ammonia on Growth}

164 The experimental conditions presented in this study include free- $\mathrm{NH}_{3}$ concentrations ranging

165 from $0.2-16 \mathrm{mg} \mathrm{L}^{-1}$ and control cases with $\mathrm{NO}_{3}^{-}$. At $\mathrm{pH}$ 8, these $\mathrm{NH}_{3}$ concentrations would 166 correspond to $3.4-339 \mathrm{mg} \mathrm{L}^{-1} \mathrm{NH}_{4}{ }^{+}+\mathrm{NH}_{3}$ and bracket typical municipal and industrial 167 wastewater stream concentrations [26]. Ammonia toxicity in photosynthetic organisms appears 168 to primarily occur through disrupting the thylakoid transmembrane proton gradient. As bulk 169 concentrations increase, $\mathrm{NH}_{3}$ freely diffuses across cell membranes, leading to increased flux 170 through the chloroplast membrane into the thylakoid lumen. In the acidic environment of the 171 thylakoid, $\mathrm{NH}_{4}{ }^{+}$forms, thereby decreasing the transmembrane proton gradient needed to power 172 ATP to ADP conversion [11,13,14]. An additional mechanism of toxicity may stem from 173 increased $\mathrm{NH}_{3}$ concentrations in the chloroplast that promote $\mathrm{NH}_{3}$ ligation to the organo-metallic

174 reactor core in the D1 protein subunit of the oxygen-evolving complex. Once ligation occurs, the 175 subunit is damaged due to destabilized electron transfer, effectively halting PSII operations $176[12,13,27]$. Though ascertaining the primary mechanism of inhibition is beyond the scope of this

177 study, each of the above mechanisms would inhibit growth and possibly effect cell physiology in 178 ways important to biofuel production.

179 Of the four species investigated in this study, two showed growth inhibition: $N$. 180 oleoabundans and D. tertiolecta (Fig.1 A and B). Nonlinear regression using the Han and

181 Levenspiel equation (eq. 1), with parameters summarized in Table 1, confirmed that growth 182 dependence on $\mathrm{NH}_{4}^{+}$followed substrate inhibition kinetics. N. oleoabundans showed 50\% 183 growth inhibition ( $\mathrm{IC}_{50}$ ), occurring near $8 \mathrm{mg} \mathrm{L}^{-1} \mathrm{NH}_{3}$. At optimal $\mathrm{NH}_{4}{ }^{+} / \mathrm{NH}_{3}$ concentrations, 184 observed growth rates for $N$. oleoabundans did not significantly differ from growth on $\mathrm{NO}_{3}{ }^{-}$, 
185 with maximum growth rates of $1.2 \pm 0.3 \times 10^{5}$ cells hour ${ }^{-1}$ on $\mathrm{NH}_{4}^{+} / \mathrm{NH}_{3}$ and $1.4 \pm 1.1 \times 10^{5}$ 186 cells hour ${ }^{-1}$ with $547 \mathrm{mg} \mathrm{L}^{-1} \mathrm{NO}_{3}^{-}(\mathrm{p}=0.05)$. Inhibition behavior in $N$. oleoabundans was also 187 observed by Li et al. (2008), who showed a $\sim 50 \%$ reduction in biomass production with $90 \mathrm{mg}$ $188 \mathrm{~L}^{-1} \mathrm{NH}_{4}^{+}$grown with $5 \% \mathrm{CO}_{2}$ compared to growth on $\mathrm{NO}_{3}^{-}$, though $\mathrm{pH}$ was not reported. $D$. 189 tertiolecta had an $\mathrm{IC}_{50}$ occurring at $8.4 \mathrm{mg} \mathrm{L}^{-1} \mathrm{NH}_{3}$. As with $N$. oleoabundans, D. tertiolecta's 190 maximum growth rate on $\mathrm{NH}_{4}{ }^{+} / \mathrm{NH}_{3}\left(1.4 \pm 0.3 \times 10^{4}\right.$ cells hour $\left.{ }^{-1}\right)$ was not different $(\mathrm{p}=0.5)$ 191 than the growth rate observed on $\mathrm{NO}_{3}^{-}\left(1.6 \pm 0.19 \times 10^{4}\right.$ cells hour ${ }^{-1}$ at $143 \mathrm{mg} \mathrm{L}^{-1} \mathrm{NO}_{3}^{-} \mathrm{mg} \mathrm{L}^{-}$

$192^{1}$ ). These inhibition concentrations for both species are significant as they occur near or before 193 stoichiometric nitrogen demands for maximum culture densities, and can act as a limiting factor 194 preventing acceptable biomass production. Assuming an average molecular formula $195 \mathrm{C}_{106} \mathrm{H}_{181} \mathrm{O}_{45} \mathrm{~N}_{16} \mathrm{P}$ [28] for microalgae and a low range final microalgae culture density of $1 \mathrm{~g} \mathrm{~L}^{-1}$ 196 dry mass results in an $\mathrm{N}$-demand of $118 \mathrm{mg} \mathrm{L}^{-1} \mathrm{NH}_{4}{ }^{+} / \mathrm{NH}_{3}$. At this concentration and an 197 operating $\mathrm{pH} 8$, the $\mathrm{NH}_{3}$ concentration would be roughly $5.6 \mathrm{mg} \mathrm{L}^{-1}$; well into the inhibition zone 198 for both species, which begin at 2.3 and $3.3 \mathrm{mg} \mathrm{L}^{-1} \mathrm{NH}_{3}$ for N.oleoabundans and D. tertiolecta, 199 respectively. 
Table 1. Summary of growth parameters for $\mathrm{NH}_{3}$ inhibited alga

\begin{tabular}{cll}
\hline Parameter & N. oleoabundans & D. tertiolecta \\
\hline $\mathbf{k}_{\mathrm{MAX}}$ & $2.9 \times 10^{5}$ & $2.5 \times 10^{4}$ \\
$\boldsymbol{n}$ & 2.2 & 1.3 \\
$\mathbf{m}$ & -0.14 & 0.44 \\
$\mathbf{K}_{\mathbf{m}}$ & 2.6 & 0.6 \\
$\mathbf{K}_{\mathbf{i}}$ & 16.4 & 16.4 \\
$\mathbf{I C}_{\mathbf{5 0}}$ & 7.7 & 8.4 \\
$\mathbf{I C}_{\mathbf{1 0 0}}$ & 15.9 & 16.4 \\
$\mathbf{R}_{\mathbf{C , N H 4 +}}$ & $1.2 \times 10^{5} \pm 1.1 \times 10^{4}$ & $1.4 \times 10^{4} \pm 2.9 \times 10^{3}$ \\
$\mathbf{R}_{\mathbf{C , \text {NO3-}}}$ & $1.41 \times 10^{5} \pm 1.1 \times 10^{4}$ & $1.6 \times 10^{4} \pm 5.4 \times 10^{3}$ \\
\hline
\end{tabular}

$\mathrm{k}_{\mathrm{MAX}}$ (calculated maximum growth rates), $\mathrm{R}_{\mathrm{c}, \mathrm{NH} 4+}$ and $\mathrm{R}_{\mathrm{c}, \text { NO3- }}$ (growth rates for $\mathrm{NO}_{3}$ and $\mathrm{NH}_{4}$, respectively) reported as cells hour $^{-1} . \mathrm{K}_{\mathrm{m}}$ (Monod half-saturation concentration), $\mathrm{K}_{\mathrm{i}}$ (inhibition concentration), $\mathrm{IC}_{50}$ (50\% growth inhibition concentration), $\mathrm{IC}_{100}$ (complete growth inhibition concentration) reported as $\mathrm{mg} \mathrm{L}^{-1} . m$ and $n$ are unitless constants that account for observed changes to $k$ and $K_{m}$. Parameters $\mathrm{k}_{\max }, m, n, \mathrm{~K}_{\mathrm{m}}$ and $\mathrm{K}_{\mathrm{i}}$ were optimized for best fit.

215 The two remaining species of this study, C. sorokiniana and N. oculata, did not show growth

216 inhibition due to $\mathrm{NH}_{3}$ over our experimental concentrations (Fig.1 C and D). This lack of

217 inhibition (ANOVA p > 0.4) has been previously demonstrated in another Chlorella species, $C$.

218 vulgaris, which maintained comparable growth rates up to $1000 \mathrm{mg} \mathrm{L}^{-1} \mathrm{NH}_{4}{ }^{+}$at neutral $\mathrm{pH}(4.7$

$219 \mathrm{mg} \mathrm{L}^{-1} \mathrm{NH}_{3}$ ) [29]. However, each species did express an apparent growth preference for $\mathrm{N}$ -

220 sources. The growth rate of C. sorokinana, on $123 \mathrm{mg} \mathrm{L}^{-1}$ as $\mathrm{NO}_{3}{ }^{-} \mathrm{N}$ was 1.75 times greater than

221 the average growth $\left(2.3 \pm 0.2 \times 10^{5}\right.$ cells hour $\left.{ }^{-1}\right)$ over experimental $\mathrm{NH}_{4}^{+} / \mathrm{NH}_{3}$ concentrations

$222(\mathrm{p}=0.02)$. On the other hand, $N$. oculata showed a clear substrate preference for $\mathrm{NH}_{4}^{+} / \mathrm{NH}_{3}$ as

223 a $\mathrm{N}$ source with an average growth rate outpacing nitrate growth by 4.5 times, at $1.2 \pm 0.1 \times 10^{5}$

224 cells hour $^{-1}$. 

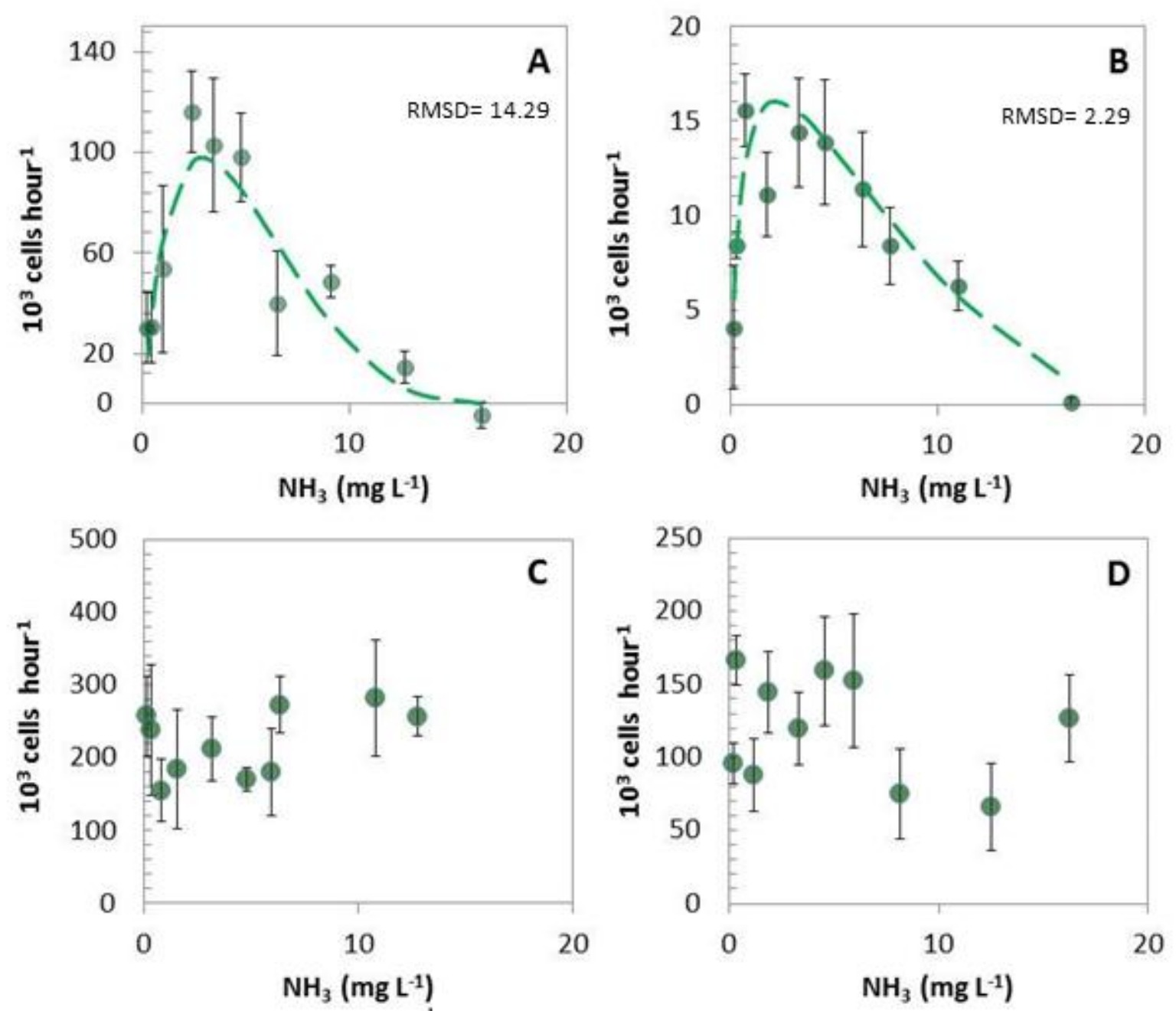

227 Figure 1. Growth rate versus free $\mathrm{NH}_{3}$ curves for each species: (A) N. oleoabundans, (B) D. tertiolecta,

228 (C) C. Sorokinana, and (D) N. oculata, represented by shaded circles, reported as cells hour ${ }^{-1}$ over $\mathrm{NH}_{3}$

229 concentrations. The error bars indicate the standard deviation of the slope from linear regression for each

230 growth rate experimental condition. The output of the substrate inhibition model using eq 1 is represented

231 by the dashed line. The Root Mean Squared Deviation (RMSD) was used to evaluate the goodness of fit 232 of the curve fitting.

234 Responses to $\mathrm{NH}_{3}$ may provide some insight into the toxicity mechanism as reflected in the expression of inhibition and the resulting model constants. As PSII is damaged, substrate (light) 
236 utilization would be reduced. Based on comparisons of unitless constants $\mathrm{n}$ and $\mathrm{m}$, Han and

237 Levenspiel categorized six common growth inhibition patterns [25]. By utilizing this

238 framework, noncompetitive inhibition was observed in the growth inhibition model of $D$.

239 tertiolecta, with the unitless constants $n>m>0$. For the other test species that showed

240 inhibition, $N$. oleoabundans, the values for the unitless constants from eq 1 indicate a general

241 inhibition $(\mathrm{n}>0, \mathrm{~m}<0)$. While the above results found different $\mathrm{NH}_{3}$ tolerances among different

242 taxa, current literature suggests toxicity responses to $\mathrm{NH}_{3}$ in seawater and freshwater may not be

243 shared within a genus. Collos \& Harrison [30] reviewed the effects of ammonia at low free

244 ammonia concentrations and demonstrated variable toxicity responses existed within genera.

\subsection{Effects of Ammonia on Lipid Profile and Cellular Content}

247 Due to the focus on oleaginous microalgae, metabolite measurements were restricted to

248 neutral lipid content and character. Aside from the implications on productivity from cellular

249 lipid content, lipids chain length and degree of unsaturation can affect physical and chemical

250 biofuel characteristics such as viscosity, density, cold flow properties, oxidative stability and

251 cetane number [1]. The central comparisons for lipid content and character for each species were

252 made through growth media containing $\mathrm{NO}_{3}{ }^{-}$as the $\mathrm{N}$ source versus growth media containing

$253 \mathrm{NH}_{4}{ }^{+} / \mathrm{NH}_{3}$ as the $\mathrm{N}$ source. For the $\mathrm{NH}_{4}{ }^{+} / \mathrm{NH}_{3}$ cases, two $\mathrm{NH}_{3}$ concentrations were considered

254 and are denoted as LOW and HIGH. Ammonia concentrations for the LOW conditions were 3.3

255 (63), 3.3 (63), 3.2 (63), and $3.3(63) \mathrm{mg} \mathrm{L}^{-1} \mathrm{NH}_{3}\left(\mathrm{NH}_{4}{ }^{+}\right)$for $N$. oleoabundans, D. tertiolecta, $C$.

256 sorokiniana, and $N$. oculata, respectively and corresponded to concentrations that were not

257 inhibitory to these taxa. The $\mathrm{NH}_{3}$ levels for the HIGH conditions were 16.0 (314), 11.5 (236),

25812.8 (315), and 16.3 (315) $\mathrm{mg} \mathrm{L}^{-1} \mathrm{NH}_{3}\left(\mathrm{NH}_{4}{ }^{+}\right)$for $N$. oleoabundans, D. tertiolecta, $C$. 
sorokiniana, and $N$ oculata, respectively and for the taxa that showed inhibition, corresponded to

260 concentrations at least 3.5 times the concentrations where inhibition begins and 1.4 times the

$261 \mathrm{IC}_{50}$.

262

263 3.2.1 FAME concentration

264 Table 2 (see Table S1 for reported standard deviations) indicates that lipid content for $N$.

265 oleoabundans, C. sorokiniana and $N$. oculata were not significantly different between $\mathrm{NO}_{3}{ }^{-}$and

$266 \mathrm{HIGH}$ and $\mathrm{LOW} \mathrm{NH}_{3}$ conditions with average total neutral lipid content reported as fatty acid

267 methyl esters (FAME), measuring 7.2\%, 7.3\% and 17.2\% respectively. These values are similar

268 to total FAME values reported in prior studies. Rismani-Yazdi [31] and Soh [32] both used an

269 identical N. oleobundans strain and reported FAME values between 5\% and 10\%. Similarly,

270 lipid content with N. oculata, had reported values of $20 \%$ and $18 \%$ neutral lipid content. The $7 \%$

271 FAME value for $C$. sorokiniana is within the $6.6 \%$ to $12 \%$ range previously reported in the

272 literature [32-34]. The remaining species, D. tertiolecta, showed statistically significant changes

273 to the lipid content between the conditions. For D. tertiolecta grown on $\mathrm{NO}_{3}^{-}$, lipid content was

$2746.3 \%$, LOW $\mathrm{NH}_{3}$ was $8.5 \%$ and $\mathrm{HIGH} \mathrm{NH}_{3}$ was $11.0 \%$ dry biomass $\left(\mathrm{NO}_{3}{ }^{-}\right.$vs LOW: $\mathrm{p}=0.02$,

$275 \mathrm{NO}_{3}{ }^{-}$vs HIGH: $\mathrm{p}=0.0007$, LOW vs HIGH: $\mathrm{p}=0.01$.

276

277 3.2.2 FAME characteristics

278 The variable nitrogen conditions also resulted in minor changes in lipid profiles for $N$.

279 oleoabundans, $C$. sorokiniana and $N$. oculata. For $N$. oleoabundans, the fresh water species that

280 exhibit growth inhibition when exposed to high levels of free ammonia, the $\mathrm{HIGH} \mathrm{NH}_{3}$

281 condition resulting in a small $(\sim 2 \%)$ but significant $(\mathrm{p}<0.01)$ decrease in polyunsaturated fatty 
282 acids (PUFA) and an equally small $(\mathrm{p}=0.01)$ increase in monounsaturated fatty acids (MUFA).

283 Other significant alterations occurred with $\mathrm{C} 18$ lipids, with the change from $\mathrm{NO}_{3}{ }^{-}$to $\mathrm{NH}_{3}$ and

284 LOW to $\mathrm{HIGH} \mathrm{NH}_{3}$ resulting in a reduction of $\mathrm{C} 18: 3\left(\mathrm{NO}_{3}>\mathrm{LOW}>\mathrm{HIGH}: \mathrm{p} \leq 0.01\right)$, and the

285 transition from $\mathrm{NO}_{3}{ }^{-}$to $\mathrm{NH}_{3}$ resulting in an increase in $\mathrm{C} 18: 2$ content $(\mathrm{p} \leq 0.01)$. While not

286 showing any growth inhibition when exposed to high levels of $\mathrm{NH}_{3}$, C. sorokiniana

287 demonstrated a small, but statistically significant increase in MUFAs, (all cases: $\mathrm{p}<0.02$ ). This

288 increase was concomitant with an increase in C18:1 content (all cases: $\mathrm{p}<0.03$ ) from 5\% with

$289 \mathrm{NO}_{3}^{-}$to $9 \%$ with $\mathrm{LOW} \mathrm{NH} 3$ and finally $13 \%$ under $\mathrm{HIGH} \mathrm{NH} \mathrm{N}_{3}$ concentrations. Additionally, $C$.

290 sorokiniana responded to the change of $\mathrm{N}$-source by increasing $\mathrm{C} 18: 2$ content.

291 D. tertiolecta showed the most significant changes to the lipid profile between the HIGH and

292 LOW $\mathrm{NH}_{3}$ condition (Table 2). There was a significant $(\mathrm{p}<0.01)$ transition toward increased

293 overall lipid saturation during $\mathrm{NH}_{3}$ inhibition, changing from a saturation/unsaturation ratio of

2940.6 while grown with LOW free $\mathrm{NH}_{3}$ to 1.3 when growth is inhibited by $\mathrm{HIGH}$ free $\mathrm{NH}_{3}$. PUFA

295 content was greatly reduced from $52 \%$ and $47 \%$ of the lipid content for growth on $\mathrm{NO}_{3}{ }^{-}$and

296 LOW free $\mathrm{NH}_{3}$, respectively to a HIGH free $\mathrm{NH}_{3}$ content of $8 \%\left(\mathrm{HIGH}\right.$ vs $\mathrm{NO}_{3}^{-}: \mathrm{p}<0.01$, HIGH

297 vs LOW: $\mathrm{p}=0.02$ ), representing a near 6 times decrease. MUFA increased 3 times during $\mathrm{NH}_{3}$

298 induced growth inhibition, changing from $\sim 12 \%$ lipid content for $\mathrm{LOW} \mathrm{NH}_{3}$ to $35 \%$ for $\mathrm{HIGH}$

$299 \mathrm{NH}_{3}(\mathrm{p}<0.01)$. D. tertiolecta also showed a decrease in average change length when exposed to

300 high ammonia concentrations. This is due to the decrease in C18:3 (LOW vs HIGH: $\mathrm{p}=0.01$,

$301 \mathrm{NO}_{3}$ vs HIGH: $\mathrm{p}=0.01$ ) and an increase in C16:1 (LOW vs HIGH and $\mathrm{NO}_{3}$ to HIGH: $\mathrm{p}<0.01$ ). 
Table 2. Summary of FAME comparisons.

\begin{tabular}{|c|c|c|c|c|c|c|c|c|c|c|c|c|}
\hline & \multicolumn{3}{|c|}{ N. oleoabundans } & \multicolumn{3}{|c|}{ D. tertiolecta } & \multicolumn{3}{|c|}{ C.sorokiniana } & \multicolumn{3}{|c|}{ N. oculata } \\
\hline & $\mathrm{NO}_{3}$ & LOW & $\mathrm{HIGH}$ & $\mathrm{NO}_{3}$ & LOW & $\mathrm{HIGH}$ & $\mathrm{NO}_{3}$ & LOW & $\mathrm{HIGH}$ & $\mathrm{NO}_{3}$ & LOW & $\mathrm{HIGH}$ \\
\hline $\mathrm{C} 8: 0$ & - & - & - & - & - & - & - & - & - & 0.3 & 0.3 & 0.1 \\
\hline C10:0 & - & 0.5 & 0.3 & 0.5 & 0.4 & 0.6 & - & - & 0.2 & 0.4 & 0.6 & 0.2 \\
\hline C12:0 & - & 0.1 & 0.2 & 0.4 & 0.6 & 0.4 & 0.1 & 0.8 & 0.2 & 0.6 & 0.4 & 0.4 \\
\hline C14:0 & 0.6 & 0.7 & 0.4 & 0.6 & 0.7 & $\underline{4.7}$ & 0.3 & 2.4 & 0.2 & 7.2 & 10.9 & 5.6 \\
\hline C14:1 & - & - & - & - & - & - & - & - & - & 0.1 & 0.6 & 0.1 \\
\hline C16:0 & 26.3 & 24.9 & 26.0 & 27.3 & 32.3 & $\underline{44.3}$ & 30.7 & 18.5 & 26.9 & 32.0 & 21.4 & 34.8 \\
\hline C16:1 & 1.7 & 1.3 & 1.0 & 0.8 & 0.9 & $\underline{26.5}$ & 0.9 & 1.4 & 1.3 & 28.4 & 30.2 & 19.6 \\
\hline C18:0 & 3.6 & 4.4 & 4.1 & 4.9 & 5.6 & 5.7 & 3.2 & 2.9 & 3.3 & 3.3 & 2.5 & 4.4 \\
\hline C18:1 & 5.4 & 6.0 & $\underline{8.3}$ & 9.6 & 10.0 & $\underline{8.4}$ & 5.5 & 9.6 & $\underline{13.5}$ & 4.3 & 5.5 & 5.7 \\
\hline C18:2 & 27.1 & 30.7 & 32.0 & 8.0 & 7.6 & 2.0 & 21.5 & 37.8 & 30.9 & 3.5 & 4.1 & 3.7 \\
\hline C18:3 & 35.2 & 31.0 & $\underline{27.2}$ & 44.7 & 38.4 & $\underline{1.9}$ & 37.1 & 24.3 & 22.6 & 0.4 & 1.4 & 8.6 \\
\hline C20:0 & 0.2 & 0.4 & 0.3 & 0.3 & 0.6 & 0.7 & 0.5 & - & - & - & 0.1 & 0.5 \\
\hline C20:1 & - & - & - & 0.5 & 1.5 & 0.2 & - & 0.1 & - & - & 0.1 & 0.5 \\
\hline C20:2 & - & - & 0.2 & 2.1 & 1.4 & $=$ & - & 2.2 & 0.6 & 0.5 & 0.1 & 3.7 \\
\hline C20:3 & - & - & - & 0.3 & - & 0.4 & - & - & - & 0.7 & 0.5 & 0.2 \\
\hline$C 20: 4$ & - & - & - & - & - & - & 0.1 & - & - & - & - & - \\
\hline C20:5 & - & - & - & - & - & 4.1 & - & - & - & 18.3 & 21.2 & 11.9 \\
\hline PUFA \% & 62.3 & 61.7 & 59.5 & 55.1 & 47.4 & $\underline{8.5}$ & 58.7 & 64.3 & 54.2 & 23.3 & 27.3 & 28.1 \\
\hline MUFA \% & 7.0 & 7.3 & 9.3 & 10.9 & 12.4 & $\underline{35.1}$ & 6.4 & 11.1 & $\underline{14.8}$ & 32.8 & 36.4 & 25.9 \\
\hline SATURATION & 30.7 & 31.0 & 31.2 & 34.0 & 40.2 & $\underline{56.5}$ & 34.9 & 24.6 & 31.0 & 43.8 & 36.2 & 46.0 \\
\hline Total FAME & 7.7 & 6.8 & 7.1 & 6.3 & 8.5 & $\underline{11.0}$ & 7.3 & 7.5 & 7.2 & 18.8 & 16.0 & 16.8 \\
\hline Avg. Chain Length & 17.4 & 17.4 & 17.4 & 17.5 & 17.3 & $\underline{16.4}$ & 17.4 & 17.6 & 17.4 & 16.8 & 16.9 & 17.1 \\
\hline SAT/UNSAT & 0.45 & 0.45 & 0.45 & 0.57 & 0.67 & $\underline{1.3}$ & 0.45 & 0.45 & 0.54 & 0.78 & 0.63 & 0.85 \\
\hline
\end{tabular}

Numbers reported as percentages. Total FAME is the reported dry cell mass percentages of lipids (mg lipid per mg dry biomass).

308 SAT/UNSAT is the ratio of saturated FAME to unsaturated FAME. Bold numbers are significant $(\mathrm{p} \leq 0.05)$ with respect to $\mathrm{NO}_{3}$

$309 \quad\left(\mathrm{NO}_{3}\right.$ vs LOW, $\mathrm{NO}_{3}$ vs HIGH). Underlined numbers are significant with respect to LOW (LOW vs HIGH).

310

311 We did not observe a unified lipid response from the species investigated during exposure to

312 ammonia verses nitrate, whether or not inhibition occurred. However, the changes in lipid 
313 character might have implications on the produced biofuel's performance. Longer chain lengths

314 (heavier macromolecules) increase the density, viscosity and cetane number of the resulting

315 biodiesel [35]. Additionally, highly saturated lipids increase the produced fuels stability as they

316 are less susceptible to auto-oxidation, but also reduce the fuel's temperature dependent properties

317 such as cloud (below which the fuel will form waxes in solution) and pour (below which the

318 liquid loses flow characteristics) points [36]. The greatest changes in lipid characteristics due to

319 growth in $\mathrm{NH}_{4}{ }^{+}$were observed for $D$. tertiolecta. The changes associated with growth on $\mathrm{NH}_{4}{ }^{+}$

320 are largely beneficial for fuel characteristics as increased saturation will decrease the cetane

321 number, increase fuel stability and increase resistance to oxidation during storage. However, the

322 substantial reduction in PUFA could minimize the positive effects on cetane number and fuel

323 stability.

\section{4. CONCLUSIONS}

326 Microalgae growth schemes involving $\mathrm{NH}_{4}{ }^{+}$containing waste streams have been suggested to

327 reduce energy input from nitrogen fertilizers to support cell biosynthesis. Ammonia was shown

328 to inhibit growth in two of the four microalgae species tested at concentrations that would not

329 permit batch cultures to reach full density. These observations call into question many assertions

330 regarding microalgae life cycle analysis and the corresponding energy input reduction strategies,

331 as a significant degree of variability and nutrient sensitivity occurs among oleaginous 332 microalgae.

333

334

335 


\section{ACKNOWLEDEMENTS}

337 This research was supported by a Dubinsky Seed Grant awarded to JP. JG was supported by a 338 National Science Foundation Graduate Research Fellowship.

\section{REFERENCES}

1. Alptekin E, Canakci M (2008) Determination of the density and the viscosities of biodieseldiesel fuel blends. Renewable Energy 33: 2623-2630.

2. Pimentel D, Patzek TW (2005) Ethanol production ysing corn, switchgrass, and wood; biodiesel production using soybean and sunflower. Natural Resources Research 14: 6576.

3. Rosch C, Skarka J, Wegerer N (2012) Materials flow modeling of nutrient recycling in biodiesel production from microalgae. Bioresource Technology 107: 191-199.

4. Brentner LB, Eckelman MJ, Zimmerman JB (2011) Combinatorial life cycle assessment to inform process design of industrial production of algal biodiesel. Environmental Science \& Technology 45: 7060-7067.

5. Sturm BSM, Lamer SL (2011) An energy evaluation of coupling nutrient removal from wastewater with algal biomass production. Applied Energy 88: 3499-3506.

6. Hoffman JP (1998) Waste water treatement with suspended and non suspended algae. Journal of Phycology 34: 757-763.

7. Pittman JK, Dean AP, Osundeko O (2011) The potential of sustainable algal biofuel production using wastewater resources. Bioresource Technology 102: 17-25.

8. Peccia J, Haznedaroglu B, Gutierrez J, Zimmerman JB (2013) Nitrogen supply is an important driver of sustainable microalgae biofuel production. Trends in Biotechnology 31: 134138.

9. Hein M, Foldager MP, Sand-Jensen K (1995) Size-dependent nitrogen uptake in micro and macroalgae. Marine Ecology Press Series 118: 247-253.

10. Sialve B, Bernet N, Bernard O (2009) Anaerobic digestion of microalgae as a necessary step to make microalgal biodiesel sustainable. Biotechnological Advances 27: 409-416.

11. Y. Azov JCG (1982) Free ammonia inhibition of algal photosynthesis in intensive cultures. Applied and Environmental Microbiology 43: 735-739. 
12. Britt RD, Campbell KA, Peloquin JM, Gilchrist ML, Aznar CP, et al. (2004) Recent pulsed EPR studies of the photosystem II oxygen-evolving complex: implications as to water oxidation mechanisms. Biochim Biophys Acta 1655: 158-171.

13. Drath M, Kloft N, Batschauer A, Marin K, Novak J, et al. (2008) Ammonia triggers photodamage of photosystem II in the cyanobacterium Synechocystis sp. strain PCC 6803. Plant Physiology 147: 206-215.

14. McCarty RE (1969) Uncoupling of photophosrylation by valinomcin and $\mathrm{NH}_{4} \mathrm{Cl}$. The Journal of Biological Chemistry 244: 4292-4298.

15. Cohen RA, Fong P (2004) Nitrogen uptake and assimilation in Enteromorpha intestinalis (L.) Link (Chlorophyta): using $15 \mathrm{~N}$ to determine preference during simultaneous pulses of nitrate and ammonium. Journal of Experimental Marine Biology and Ecology 309: 6777.

16. Fan C, Glibert PM, Burkholder JM (2003) Characterization of the affinity for nitrogen, uptake kinetics, and environmental relationships for Prorocentrum minimum in natural blooms and laboratory cultures. Harmful Algae 2: 283-299.

17. Flynn KJ (1991) Agal carbon-nitrogen metabolism: a biochemical basis for modeling the interations between nitrate and ammonium uptake. Journal of Plankton Research 13: 373-387.

18. Paasche E (1971) Effects of ammonia and nitrate on growth, photosynthesis, and ribulosediphosphate carboxylase content in Dunaliellia tertiolecta. Physiologia Plantarum 25: 294-299.

19. Syrett PJ, Morris I (1963) The inhibition of nitrate assimilation by ammonium in Chlorella. Biochimica et Biophysica Acta - Specialized Section on Enzymological Subjects 67: 566575.

20. Griffiths MJ, Harrison STL (2009) Lipid productivity as a key characteristic for choosing algal species for biodiesel production. Journal of Applied Phycology 21: 493-507.

21. Groover RD, Bold HC (1969) Phycological Studies-VIII. The taxonomy and comparative physiology of the Chlorosarcinales and certain other edaphic algae. University of Texas at Austin Bulletins and Publications http://hdl.handle.net/2152/27521.

22. Ukeles R, editor (1976) Cultivation of plants: unicellular plants. London: Wiley.

23. Folch J, Lees M, Stanley GHS (1957) A simple method for the isolation and pruification of total lipides from animal tissues. Journal Biological Chemistry 226: 497-509. 
24. Morrison WR, Smith LM (1964) Preperation of fatty acid methyl esters and dimethylacetal from lipids with boron triflouride-methonol. Journal of Lipid Research 5: 600-608.

25. Han K, Levenspiel O (1988) Extended Monod kinetics for substrate, product and cell inhibition. Biotechnology and Bioengineering 32: 430-437.

26. Tchobanoglous G, Burton FL, Stensel HD, Metcalf, Eddy (2003) Wastewater Engineering: Treatment and Reuse: McGraw-Hill Education.

27. Evans MC, Ball RJ, Nugent JH (2005) Ammonia displaces methanol bound to the water oxidizing complex of photosystem II in the S2 state. FEBS Letters 579: 3081-3084.

28. Stumm W, Morgan JJ (1981) Aquatic Chemistry. New York: Wiley-Interscience.

29. Tam NFY, Wong YS (1996) Effect of ammonia concentrations on growth of Chlorella vulgaris and nitrogen removal from media. Biochemical Engineering Journal 57: 45-50.

30. Collos Y, Harrison PJ (2014) Acclimation and toxicity of high ammonium concentrations to unicellular algae. Marine Pollution Bullitin 80: 8-23.

31. Rismani-Yazdi H, Haznedaroglu BZ, Bibby K, Peccia J (2011) Transcriptome sequencing and annotation of the microalgae Dunaliella tertiolecta: pathway description and gene discovery for production of next-generation biofuels. BMC Genomics 12: 148.

32. Soh L, Zimmerman J (2011) Biodiesel production: the potential of algal lipids extracted with supercritical carbon dioxide. Green Chemistry 13: 1422-1429.

33. Griffiths MJ, van Hille RP, Harrison ST (2010) Selection of direct transesterification as the preferred method for assay of fatty acid content of microalgae. Lipids 45: 1053-1060.

34. Li T, Zheng Y, Yu L, Chen S (2014) Mixotrophic cultivation of a Chlorella sorokiniana strain for enhanced biomass and lipid production. Biomass and Bioenergy 66: 204-213.

35. Saxena P, Jawale S, Joshipura MH (2013) A Review on prediction of properties of biodiesel and blends of biodiesel. Procedia Engineering 51: 395-402.

36. Sharma YC, Singh B, Upadhyay SN (2008) Advancements in development and characterization of biodiesel: A review. Fuel 87: 2355-2373. 